\title{
Article
}

\section{More than a Match: The Role of Football in Britain's Deaf Community}

\author{
Atherton, Martin, Russell, Dave and Turner, Graham \\ Available at http://clok.uclan.ac.uk/4861/ \\ Atherton, Martin ORCID: 0000-0001-7300-2339, Russell, Dave and Turner, \\ Graham (2001) More than a Match: The Role of Football in Britain's Deaf \\ Community. Soccer and Society, 2 (3). pp. 22-43.
}

It is advisable to refer to the publisher's version if you intend to cite from the work.

For more information about UCLan's research in this area go to

http://www.uclan.ac.uk/researchgroups/ and search for < name of research Group>.

For information about Research generally at UCLan please go to http://www.uclan.ac.uk/research/

All outputs in CLoK are protected by Intellectual Property Rights law, including Copyright law. Copyright, IPR and Moral Rights for the works on this site are retained by the individual authors and/or other copyright owners. Terms and conditions for use of this material are defined in the policies page.

\section{CLoK}

Central Lancashire online Knowledge www.clok.uclan.ac.uk

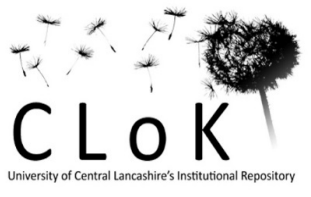




\title{
More than a Match: The Role of Football in Britain's Deaf Community
}

\author{
MARTIN ATHERTON, GRAHAM H. TURNER \\ and DAVID RUSSELL
}

\begin{abstract}
The University of Central Lancashire has undertaken a major research project into the role of football within the deaf community in Britain. As well as reconstructing the long history of deaf involvement in football for the first time, the project has also focused on the way in which football has provided deaf people with a means of developing and maintaining social contacts within the community, and of expressing the community's cultural values. This article will draw on primary data gathered from interviews conducted with people involved in deaf football in a variety of capacities. During the course of these interviews, a number of themes and issues emerged relating to the values and benefits those involved with deaf football place on the game, and it is these which are explored here.
\end{abstract}

\section{The Deaf Community in Britain}

Despite there being somewhere in the region of 8.5 million people in Britain who have some degree of hearing loss (roughly one in seven of the population ${ }^{1}$ ), only a small proportion of these regard their deafness as a part of their cultural identity. It is these who are referred to as the deaf community, although it is not possible to define who are members of the deaf community precisely, as membership is conferred rather than assumed. ${ }^{2}$ However, writers such as Baker and Cokely, ${ }^{3}$ and Padden ${ }^{4}$ have outlined the criteria which need to be fulfilled in order to become accepted into the community. Central in these criteria are the acceptance and use of sign language as the primary means of communication for deaf people. Some idea of the size of the British deaf community can be drawn from the statistic that there are only approximately 70,000 people in Britain for whom British Sign Language (BSL) is the preferred form of communication. ${ }^{5}$ This is not the total extent of the community, as other people also belong within the community, for example hearing children and partners of deaf adults, but the community is not extensive. It is this community on which this research has primarily focused.

The use of sign language plays a central role in the conduct of the community's social and cultural life. However, deaf sign language users are a widely dispersed group, and there is no geographical concentration within Britain, or indeed any country in the world, in which deaf people form the majority or sign language is the majority language. Therefore it is through social

Soccer and Society, Vol.2, No.3 (Autumn 2001), pp.22-43

PUBLISHED BY FRANK CASS, LONDON 
networks such as deaf schools and deaf clubs that deaf people have traditionally made and maintained friendships with others of a similar background and cultural perspective. Deaf people are no different from the majority of hearing people in terms of their love and enjoyment of sport, and football has been one of the major participant sports for deaf people. Indeed, there has been a continuous involvement in football by deaf players and teams since the formation of the very first deaf football club in the world; Glasgow DFC in $1871 .{ }^{6}$ Football within the deaf community has served as much more than merely a sporting or recreational pastime for the players; it has provided a means, or at times an excuse, to travel, often long distances, to meet old friends within the widely dispersed community, and an opportunity to meet and make new contacts. In many ways, deaf football mirrors its hearing counterpart, but in others, it has played a much deeper sociological and cultural role in the wider deaf community.

\section{The Role of Sport in Society}

Since before the earliest recorded history, sport has played a central role in both the social and cultural life of all civilized societies. According to Loy and Kenyon: 'Sports and recreational activities have formed a basic part of all cultures, including all racial groups and historical ages, because they are as fundamental a form of human expression as music, poetry and painting. ${ }^{7}$

There has been little previous research carried out into the social and cultural aspects of sport within the deaf community. This is despite sport having played a major role in the leisure activities of deaf people since at least the latter part of the last century, as demonstrated by the regular inclusion of reports on deaf sporting events in the deaf print media. ${ }^{8}$ The only significant work to date on this feature of deaf life is that of Stewart, ${ }^{9}$ which focuses on America. He argues that, by analysing and understanding deaf participation in sport, a clearer understanding of the dynamics and tensions of living as a deaf person in a hearing majority can be achieved. The underlying factors he identifies as the major reasons for deaf people being involved in sport, whether competing solely against other deaf people, or in competition with hearing sportsmen, largely equate with what others such as Holt ${ }^{10}$ have to say about the role of sport in society generally. There is also a large body of circumstantial and anecdotal evidence to support the assertion that sport within the deaf community has more than merely sporting attachments.

Much of this evidence comes from the pages of the deaf print media, and from the recollections of deaf people. Since the earliest days of such publications, sport has featured prominently in its pages. For example, Deaf and Dumb Magazine in 1874 carried an at times acrimonious debate between Glasgow and Manchester Deaf Football Clubs as to which was the older. This was obviously a matter of some pride to both clubs, and was finally resolved amicably when it was discovered that Manchester, although the older, was a Rugby football club, whilst 
Glasgow, who had started the debate by announcing themselves as the oldest deaf football club, were found to be an Association football club. ${ }^{11}$ Other magazines of the period contain photographs of teams and individual competitors from a variety of sports, as well as reports on matches and competitions, and this inclusion in the deaf media continues to this day. Deaf people like sport simply for the pleasure and enjoyment it can bring, as well as the physical exercise and recreation. But deaf sport also plays a number of other functions within the deaf community, just as it has for the hearing population.

\section{The Motivations for Sports Participation}

Holt argues that there are three main motivations for participation in sport, whether as players, spectators or officials. These are sociability, emotional rewards and self- and group-identity. All three have cultural attachments and implications for those involved, reflecting the social basis of all sports. Without the socialization which accompanies attachment to a sports club, sporting activity would not be attractive as a leisure pastime: 'Sport is about making friends, building communities, sharing experiences'. ${ }^{12}$ Through the sociability offered by sport, its participants can gain the emotional rewards it offers, and achieve a sense of identity, both of themselves as individuals and as members of a social grouping.

Holt illustrates the way in which many groups joined together to pursue sporting activities from amongst the members of social clubs, such as working men's clubs and Old Boys' associations. This was exactly the way in which deaf football clubs were formed, based exclusively in the early years in deaf schools and deaf clubs. In both cases, sport was a means of maintaining and strengthening existing social ties, as well as providing an opportunity for attracting others of a similar background into the social circle of the group or community. Taylor and Ward relate Holt's point to football, when discussing the rationale for their oral history of professional football, Kicking and Screaming; 'football is not all about a ball, it is about the relationships that the ball provides'. ${ }^{13}$

\section{Membership of the Deaf Community through Sport}

Within deaf football, the relationships formed between those involved in the game play a similar sociological role. Padden ${ }^{14}$ names sport as one of the social elements by which deaf people maintain contact with each other. Sports such as football act as a means by which the culture of the deaf community is passed down to other members, by providing an opportunity for deaf people to meet and exchange experiences and information. Lawson agrees with Padden, listing sport as one of a number of ways in which deaf people form 'a cohesive and mutually supportive community'. ${ }^{15}$ This aspect of deaf sport mirrors Holt's findings that sport is one means by which a group or community's collective life can be sustained, and the way in which sport can be 'a source of cultural continuity 
between generations'. ${ }^{16}$ This is of particular significance within the deaf community, as approximately 90 per cent of deaf children are born to two hearing parents, ${ }^{17}$ deaf sport can thus provide them with an access to the culture and traditions of the deaf community which they might not otherwise have. Higgins ${ }^{18}$ outlines three criteria for membership of the deaf community, based on experience of deafness, identification with the deaf community and involvement in the deaf community. For deaf people engaged in a deaf sports club - whether playing against deaf or hearing opponents - conforming with these criteria can allow them a means of entering into the life of the deaf community. The avenues to membership identified by Baker and Cokely ${ }^{19}$ would also seem to allow at least partial membership to be conferred on deaf sportsmen and women, through the social and audiological routes of admission. Sport allows deaf people who are not yet immersed in the deaf community to experience its culture and social aspects without having to commit themselves fully to membership: 'Sport offers deaf athletes an opportunity to test the social environment of the deaf community without fully adapting to its social and communicative demands' ${ }^{20}$ Not all deaf people want to be involved in the deaf community, or possess the signing skills required for full membership; joining a deaf sports club allows deaf nonmembers an opportunity to assess if they wish to become more deeply involved with the community, through meeting and socializing with its members, and improving their signing skills.

\section{The Importance of Socialization for Deaf Footballers}

Holt argues that the basis of all sport is sociability, centring on clubs and associations of like-minded people, and as such is 'a way of sustaining collective life'. ${ }^{21}$ Wohl and Pudelkiewicz contend that the most successful sporting organizations are those which best satisfy local needs for socialization, and the long history of football within the deaf community would suggest that this is certainly true of deaf football. ${ }^{22}$ Reports in the deaf media have frequently carried references to the social events attached to the matches between deaf teams. However, as this research has shown, deaf footballers have also always been involved with what they characterize as 'hearing teams', either as players in such teams or playing for deaf teams in hearing leagues. Stewart contends that this results from deaf footballers having different motivations for being involved in each; hearing sport provides physical gratification, whilst participation in deaf sport is more socially rewarding. ${ }^{23}$

\section{The Emotional Rewards of Involvement in Deaf Football}

Deaf football has always been a way of bringing deaf people together, and the deaf community has always placed a value on the way team sports can help to maintain social and cultural ties amongst its geographically dispersed members. By 
meeting and mixing with other deaf people, the culture of the deaf community has been maintained and passed on to younger deaf people. For many young deaf people, their first experience of deaf culture and entry into the social life of the community has come about as a result of being involved with the deaf football team:

When I was younger, I wasn't interested in the deaf club, I thought it was boring, but then I followed my brothers into the football team and got involved that way. ... All the deaf people in [place name] knew each other, they knew where everyone lived. You could go to someone's house and say, 'I remember you from school. Do you want to come and join the deaf football club?' and they would say yes. ${ }^{24}$

Certainly within deaf football circles, the assertions of Taylor and Ward that football is more than just a game can be seen to be true. ${ }^{25}$ For this ex-player, the socializing that followed matches against other deaf clubs contrasted with matches played against hearing opponents in the league:

Subject A: Oh, yes, the socializing was important as well, having the chance to meet friends, have a chat in the deaf club. We always used to go to the deaf club with our friends after a match. Some people would go home, but they always went to the deaf club for a while first. Or if there was nothing on at the club, we might go to a local pub or go for something to eat.

Interviewer: When [team name] were playing in the hearing league, would the players go for a drink with the hearing players after the match?

Subject A: No, never. We used to keep apart from the hearing teams. A few might have mixed, but at [team name], we used to keep separate, we used to get changed and go off to the deaf club.

An older player remembers the part socializing played in the overall experience, when his deaf football club travelled to away matches in the British Deaf Cup:

Interviewer: When you had a match and socialized afterwards, which was more important, the match or the socialising?

Subject B: The match [smiling], but afterwards in the evening when we met other deaf people, that was interesting. Meeting a variety of people, signing, seeing different signs. Both were important.

Interviewer: But was a match sometimes an excuse to travel and socialize?

Subject B: Yes, you're right. When we were drawn away against another team, we were really interested in going there to meet them, playing the match and then socializing. That's why it was interesting, meeting different people. 
Such trips can also be a means of renewing or rekindling friendships with other deaf people:

Subject C: When we played away at [team name], it was nice to see some old faces again. I hadn't seen some of them for 20 or 25 years, and it was really good to shake hands and talk about old times, renew old friendships.

The numbers travelling to such matches could be quite large, given the comparatively small number of deaf people in any area:

Subject C: I remember when we reached the final [of the British Deaf Cup], we played [team name] and the match was arranged so that we met halfway. We had the team and a lot of supporters to take - all together there were about 70 or 80 people who wanted to go, but the biggest coach we could get was a 50 seater. Then I had the idea of hiring a double decker bus, so that we could get everyone on, so that's what we did!

This was at a time when this particular deaf football club had trouble attracting more than 15 or 16 players from a local deaf population of around 800 people. Nevertheless, the opportunities offered by the social events which generally followed such matches was no doubt a big incentive for many to travel with the team, whether they were actually interested in the football itself or not.

\section{Crossing Language Boundaries}

This cultural exchange was not limited to matches taking place between British teams; socializing is just as important when international matches are played. Deaf football also allows international communication boundaries to be crossed, often more easily than may be the case for hearing teams. It is a common misconception that sign language is universal, and that all signers understand each other's signing in spite of nationality. In fact, there are a large number of distinct sign languages spread across the globe, and within each, regional dialects can be found, just as in spoken languages. However, there are similarities in the grammatical structures of signed languages and the formation of individual signs. Sign language also has a visual basis, and it is through these elements of the language that deaf people from different countries can find common links within their languages which allow a hybrid form to be constructed for informal communication. ${ }^{26} \mathrm{~A}$ former member of the Irish deaf international team recalls playing against France, and the way both teams adapted their sign language to facilitate communication:

After the football finished, we were all happy because we had won, but we were aware that the French were looking a bit unhappy - it's always the same, in all football! Anyway, after we had all got changed, we went on a coach to a hotel for a meal - both teams. The room was laid out with long 
tables, and we sat on one side and they sat on the other, facing us. We would start signing to each other, and really communication wasn't a problem. The French would adjust their signing a little bit, and the Irish lads would do the same, and between us we managed to find a common form of language. Plus we used eye contact a lot, and that made it much easier to communicate. Because we all made these alterations, and some of the signs in French and Irish sign languages are similar, we managed to communicate really well. Exactly how it happens, I can't say, but it does! $!^{27}$

Others remember the socializing that followed international matches, particularly an England trip to Belgium:

Subject C: We always mixed, there were never any problems. At international matches, it didn't matter if we played at home or away, there was always a good welcome for the visitors. Someone would show the players to the hotel, where to eat, take the players on a sightseeing tour. At night, there would be a big meal, all the teams would be sat together, go out for a drink after. We were all relaxed together, it didn't matter if we won or lost.

Subject E: Do you remember when we went to Belgium? We all socialized that night - we were out until 5 o'clock in the morning!

Subject C: I remember playing football with a cigarette packet when we were all legless! Next morning, I was covered in bruises but I didn't know why! Playing abroad we never had any problems.

\section{Collective Experience through Sport}

Holt sees the emotional rewards of involvement in football as coming from the collective experiences of shared values and objectives which involvement in a team sport can provide. ${ }^{28} \mathrm{He}$ argues that the number of players involved in a team is small enough to allow collective bonding and intimacy as a group, but large enough to allow a variety of social relationships and interactions to be formed within sub-groups of the whole. In this way, players can be a part of the whole without having totally to subsume their personal interests or identity to that of the majority. They can retain their individuality, and form closer bonds with similar team members, without losing their sense of belonging within the larger group identity. Team sport thus allows emotional satisfaction and release to be achieved on a variety of levels within one social group setting in a way which is not possible to achieve to the same extent in sports based on individual performance. Sport can play an important role as an emotional release from the tensions and pressures inherent in life in modern industrialized societies. ${ }^{29}$ An example of this from football is given by Davies' investigation of women's football. ${ }^{30} \mathrm{He}$ found that being involved in a women's football team provided a 
purpose and emotional sustenance which was missing from the lives of many of the club's players and supporters. Many were unemployed or in low status jobs, or suffering personal and social problems, mostly caused by living in an area undergoing major upheavals within the fabric of community life. The players' involvement in football gave them an emotional release for the stresses resulting from these conditions, and also provided an alternative community structure in which they could experience some degree of success and gain some self-esteem. In doing so, football served as an antidote to the negative elements present in the lives of many of the players.

\section{Wider Socialization through Football}

Many deaf people are avid watchers of professional football, and the following extract illustrates the way some deaf people will use football as a means of maintaining social contact, even if, as in this case, they may have little interest in the sport itself:

I remember being with a group of [deaf] friends at one time - back in Euro 96, and the World Cup in 1998 as well - some of my friends weren't very interested in football, but I had agreed to go to the pub to watch England against Scotland. I told my friends and asked them if they wanted to come with me and have a drink. Some other [deaf] friends asked us where we were going, and when we told them we were going to the pub to watch the football, they decided to come along, even though they weren't interested in football. They wanted to learn about football, so that they could be a part of the group - they didn't want to be left out. It was interesting - they obviously didn't know the rules of football, and they would say something that made us laugh. That's when I realised that they had come along so that they wouldn't be left out of the group. ${ }^{31}$

The above experiences provide an example of one of the ways in which deaf football can support the maintenance of contact within the deaf community, and so play a role in the cultural life of the deaf community beyond that of mere sporting activity. It was apparently the opportunity to be with other deaf people which was the motivation here, rather than an interest in football. Holt's assertion that 'Sport is about making friends, building communities, sharing experiences' ${ }^{32}$ can certainly be seen to apply to football in the deaf community, providing as it does a means by which deaf people can share the beliefs and values of the deaf community, whether they are interested in the actual football itself or not.

\section{The Importance of Communication}

Communication is often the central factor in making involvement with a deaf team attractive to deaf players. Many deaf footballers find themselves isolated by 
a lack of communication with hearing team-mates; on the pitch this was not always a problem, but in the bar or pub afterwards, deaf players with hearing teams find themselves excluded from the social life of the team:

Subject C: During training or a match, I was involved, but when the referee blew the whistle for the end of the match, that was it - finished. When we went back to the changing room, I would be in the corner on my own, and the hearing players would be over there in a group talking. No-one came up and said 'Well done' or ' $1-0$, great'; there was no communication at all. Now, people speak to me, but at that time ... Some coaches and managers tried to encourage me to join in, but it wasn't easy - I felt left out really.

Subject G: When the hearing team's match finished, we would go for a drink in the pub, and it was all a bit flat. The hearing players would all gather in a group talking, and the deaf players would be left on our own. When a deaf match finished, we would all be together, signing away and it was much more enjoyable in that respect. ${ }^{33}$

At least this last player had the advantage of having deaf team-mates with whom he could socialize, and who could offer each other mutual support. For many deaf footballers, being involved in hearing teams can remain an unfulfilling experience, despite the higher standards of football. The social side of deaf football which results from being able to communicate freely with each other is a powerful alternative attraction:

Subject C: When I played for hearing teams, I felt left out because I was the only deaf person there, that's why I joined the deaf team in [place]. I enjoyed that because we could mix, socialize, there was good communication.

Subject $\mathrm{H}$ : I became involved in deaf football because the communication is better. I used to play for a local Sunday league team, and I really enjoyed the football side of it, but there was no communication there. After the match we would go to the pub, and the others would talk about the match, but I wasn't included. I didn't even know their names - there was only one person whose name I knew.

\section{Deaf Empowerment through Sport}

Sport can bring deaf people together in a setting where they are not isolated by communication barriers or seen as being different or abnormal because of an inability to hear. By providing deaf people with a means by which their social and psychological needs are fulfilled - in a way which is absent from their daily lives amongst a hearing majority who do not fully understand them, or with whom communication is at best limited - deaf sport can provide the emotional rewards 
that Holt contends derive from participation in sport. In doing so, deaf sport has a power to be an influence for good far beyond the boundaries of the sports field. Holt feels these rewards arise from the 'shared values and objectives ... and collective experiences' of members of a sporting team or club. ${ }^{34}$ Within a deaf sporting context, a deaf person is no longer excluded from social congress by a lack of hearing: 'To be normal in deaf sport, a person has to be deaf' ${ }^{35}$ Deaf sport thus presents deaf people with a rare opportunity to belong to a mainstream rather than a marginal - group. This in itself is an unusual situation for deaf people. Within this environment of normality, positive influences can come to bear on the way deaf sportsmen view themselves and their place within both the deaf community and the larger society. When participating in sporting activity, deaf sportsmen do not have to contend with all the barriers they meet on a daily basis in their non-sporting lives. Problems of low self-esteem, inadequate education and job opportunities, discrimination and negative perception, and an inability to have effective communication with the hearing majority are all difficulties that can be put aside whilst involved in deaf sport. This contrast with the usual experiences of deaf people is defined thus:

'Deaf sport emphasizes the honour of being deaf, whereas society tends to focus on the adversity of deafness'. ${ }^{36}$

This can be achieved through the support networks which result from having contact with other deaf sportsmen and women. This ex-player feels that being involved with his deaf football club benefited him personally:

I think that it made me more confident. Maybe if I hadn't got involved with the football, I wouldn't be the person I am today. ${ }^{37}$

Many of the current leaders of UK deaf organizations and deaf people in professional positions have also been successful sportsmen and women, and there may be some link between these two areas of achievement. ${ }^{38}$ They can thus serve as role models through whom positive alternatives to the negative stereotypes faced by deaf people can be developed. These role models are largely missing from other areas of life such as employment and education, and deaf sports organizations are a means of providing young deaf people with deaf adults whose achievements they can seek to emulate. This is particularly important for school age deaf children, many of whom have little or no access to deaf adults, and so largely see only hearing people in positions of power or authority. A consequence of this is that they may perceive deaf people as being inferior or subservient to hearing people. ${ }^{39}$

\section{Awareness of Wider Issues gained through Deaf Football}

Involvement in football can provide deaf people with insights into aspects of the wider community they may not have encountered before, such as racism and religious segregation. Therefore, it can serve an educational purpose: 
I remember going to [place] I think that's who we were playing - oh, no, it was a Northern Irish team, [name], that's it. We had a black player, do you remember? I think it was in the $80 \mathrm{~s}$. We went over there, and they were all looking at him because he was black. It was really - we were all amazed, but he didn't bother, and we all went out at night for a drink. We went in a hearing bar, and again, they were all looking at him as if he was something strange. It was really unusual to us to see such a reaction! $!^{40}$

I joined a [hearing] club in [place]. There was a deaf player there who knew me, and he invited me to go along and play for them. He was the only deaf player, and it was good for him to have me there. I had only recently moved to Northern Ireland, and I wasn't aware that there were different areas, or how sensitive it all was, with strong Catholic and Protestant areas - I just didn't know! When I found out, I was really shocked. ${ }^{41}$

\section{Identity through Sport}

All the above examples illustrate the impact of Holt's third factor, that of self and group identification through sport. In the earlier example from women's football, the deterioration of the traditional way of life of the area lead to a loss of identity, both for individuals and as a community. By being involved in the football club, both the female players and officials and supporters of both sexes were able to regain a sense of belonging and group identity. This provided those involved in the club with the means to sustain the collective life of their footballing community, and by extension the community within which the players lived and the club functioned. In this way, Davies provides an example of how sports clubs can replace local social networks when those networks fail to provide the social cohesion required within a community or society. ${ }^{42}$ This is particularly important when the football clubs are comparatively successful, both locally and on a national level. The community is provided with a means of showing itself in a positive manner, and responding to the negative way in which it is portrayed by outsiders. Within the deaf community, self and group identification is gained in a slightly different way.

\section{Deaf Identity through Sport}

Deaf sport can provide some of its participants with an identity they may have lacked before; again linked to the fact that the majority of deaf children are born into hearing families. Stewart gives an example of a deaf woman who, until she became involved in organizing deaf sport, had no links with the deaf community. Her sign language skills were weak, reducing her ability to communicate with members of the deaf community, and she had little contact with deaf people or deaf culture. Once involved in a sporting capacity, she was able to gain an insight 
into the life of the deaf community, and so begin to identify herself with its members. Sport provided her with the motivation she had lacked to become more involved with the deaf community. ${ }^{43}$

Lawson argues that the deaf community has been isolated from the activities pursued by the hearing majority through negative attitudes and perceptions of deaf people and their abilities. ${ }^{4+}$ Football allows deaf people to share activities with hearing people on an equal footing. However, the negative attitudes she outlines often remain; this is reflected in the experiences of many deaf footballers who play against hearing opponents.

\section{Hearing Attitudes towards Deaf Players}

The attitude of hearing team-mates and opponents can be a determining factor in deaf footballers choosing to join a deaf football club:

Subject G: When you play with hearing players, they treat you like you are stupid. You tend to be left out of things. When you play with other deaf players, you can play as a team. When one deaf player is in a hearing team, he gets picked on and talked down to.

Subject C: My view is that if a deaf player is in a hearing team, and he does something good, the other players all give him the thumbs up and make a great show of praising him. Why? They are just being patronizing.

Playing in a hearing team can also be a frustrating experience on the field on occasions:

One of the hearing teams I played for - when I played my first match, I waited and waited for the ball, but no-one passed to me. I kept waving for the ball, but they just passed to each other; after about 30 minutes, I thought there's no point me playing. I was bored - I think I had the ball ten times in the match. ${ }^{45}$

These examples show the way in which being a member of a hearing football team is often not as socially rewarding for deaf players as belonging to a deaf team. Not everyone has negative experiences of being involved in a hearing team. However, in the following extract, a deaf woman footballer shows how she managed to be involved in the social side of her women's team in which she was the only deaf player. In common with other deaf players in hearing teams, she had little communication with her hearing team-mates, but she developed a strategy for being involved in the social life of the club which precluded the need to attempt to communicate:

When training finished, we didn't bother getting changed, we all went straight to the pub to have a pint, play pool. At the end of the night, when they [the hearing players] were all drunk, they would start singing; that's 
wasn't really part of my culture - drinking, playing pool - but at the time it was good. Every Wednesday night, because I was in the pub with hearing friends, conversation was superficial, but we had a laugh. My deaf friends knew I went to the pub with hearing friends every week, and they always knew they could find me there. Really, I wasn't involved in any conversations or anything. When I arrived at the pub, I would go straight to the pool table. That way, we didn't need to try and communicate. If there wasn't a pool table, we would have had to sit around and talk. Sometimes, I would ask my deaf friends to come and meet me at the pub, to act as support. Also, every Wednesday you would see the same faces, and they would invite you to have a drink or a game of pool, so that helped. ${ }^{46}$

\section{Relationships between Deaf and Hearing Footballers}

Deaf people face barriers in their everyday lives owing to the lack of communication between themselves and the hearing majority, and as a consequence of this many deaf people feel they have been oppressed by hearing people throughout history. Football provides deaf people with an opportunity to compete with hearing people on equal terms; something which is not always possible in other areas of life such as education and employment. However, the prejudices and misconceptions deaf people face in other walks of life are also to be found when dealing with hearing players:

Subject I: Some hearing people think that deaf people can't play as a team, but why not? We've got legs, we can't hear but we can see - we have eyes!

\section{A Distrust of Hearing Officials}

This feeling of oppression has lead many deaf people to have a deep distrust of hearing people, and this distrust is apparent amongst deaf people engaged in football against hearing opponents; many deaf players feel they are treated differently from their hearing opponents, both on and off the pitch.

Subject H: Sometimes, deaf players feel that hearing teams have 12 players. If a deaf player does a bad foul the referee always blows up, which is fair enough, but if a hearing player does a bad foul, it's always, 'Play on!'.

A lack of deaf awareness can also adversely affect individual deaf players, as shown by the following incidents:

Subject I: Remember that match that was abandoned? The referee thought someone had punched him, but the [deaf] player had just tapped him on the shoulder! Unbelievable! 
Subject G: It's deaf culture to tap someone on the shoulder, and he tapped the referee's shoulder to attract his attention. The referee sent him off and abandoned the match, because the ref. thought he had been hit, but it was just deaf culture, he only wanted to attract the ref.

Subject I: The [County] FA say, 'We support deaf football', but there was a big argument about the abandoned match, because there was no deaf awareness then. They said, 'You shouldn't prod the referee, you should shout to him'. I think they should book some deaf awareness training, because it's a real problem.

Interviewer: Are the referees more aware now?

Subject H: No, it's still the same this season, one of our players was sent off in a match before Christmas. The referee asked him his name, but he couldn't lip-read what the player was saying, so the player wanted to write his name in the ref's book. The referee just kept saying, 'No, tell me your name', but the player couldn't make the referee understand, so eventually he [the player] walked away. So the referee wrote in his report that the player refused to give his name, but that wasn't true, he just wanted to write it down for the referee, but the ref wouldn't let him.

Subject I: He had no deaf awareness, that's why.

\section{The Advantages of Being Deaf in Hearing Football}

Despite the negative views expressed above concerning the perceived attitudes of hearing referees towards deaf footballers, there can sometimes be certain advantages for players who are deaf, especially when playing with hearing teams:

Subject D: If I fouled someone, I used to get away with it by saying I was watching the ball; the referees used to wag their finger at me, and tell me it was my last warning, but I never got booked. They just used to keep giving me last warnings, because they didn't know how to communicate with me.

Interviewer: Do you think you would have been booked if you were a hearing player?

Subject D: Definitely!

Subject F: Sometimes if I committed a foul, the referee would tell me off, and then just let me go. I think I may have got away with some things because I was deaf!

Referees feeling unable to communicate effectively with deaf players may be the cause of such attitudes. However, this is a common problem in international football at all levels, when referees do not speak the language of one or both teams. 
Nevertheless, they still manage to communicate their decisions and warnings by gesture. Therefore, referees may in fact be treating deaf players more leniently because they hold preconceived ideas based on their deafness. They may have conceptions of the abilities of deaf players based on medical or pathological models of deafness, which emphasize that which is seen to be missing or lost by a deaf person when compared to a hearing person, and so be adjusting their adjudication accordingly. When there may be some degree of justification for making such adjustments, they do not always occur; for example, when deaf players fail to respond to the referee's whistle:

Subject G: I used to play for my local Sunday morning team - I was the only deaf player - and once when we were playing, I didn't realize the whistle had blown. The referee knew I was deaf, but he still booked me for wasting time. That's the attitude of some referees.

Some deaf players also tell of referees refusing to use visual as well as aural methods of controlling the game, and displaying what they feel are negative attitudes towards deaf players:

Some referees have an attitude problem. A few of them are good, they use clear gestures and their attitude is good, and they get on with the game. Others look at you as if to say, 'deaf shouldn't be playing football, they should be in their own deaf football league'. I feel it is hard work when we get one of those refs. ${ }^{47}$

\section{Deaf and Hearing Attitudes to Each Other - a Motivating Factor for Both}

Deaf players' opinions of the attitudes displayed by their hearing opponents vary, no doubt influenced by their individual experiences. Some have encountered little or no difficulties with opponents, whilst others obviously feel they have been unfairly treated; their reactions vary accordingly:

Subject A: Communication wasn't really a problem during the match, everything was alright really, and we played there [in hearing leagues] for a long time. The other players attitudes were alright - well a few weren't, but most of them were fine.

Subject F: Some people would patronize me if I missed something, maybe laugh at me. If they teased me, I would just ignore it. I never looked at the other team's attitude, I was concentrating all the time. All I was bothered about was my team's attitude and having their support.

Subject D: There was a little bit [of teasing] but I just used to ignore it - I used to think it was happening because I was playing well, and the other player was getting frustrated. I just used to laugh, but when the player had 
the ball, I used to foul him, kick him up in the air! I think I did it subconsciously!

Subject I: Because of the hearing attitude towards deaf players, it makes me really determined to beat them.

Hearing teams are often equally motivated to beat deaf teams, because of the way they perceive deaf people generally, according to some deaf players:

Subject E: Before a match, we [the deaf team] would get on alright with the other [hearing] team. If we beat them - say $3-0$ or $1-0$ - then nobody spoke to us after the match. Maybe they were embarrassed to be beaten by a deaf team ... Before the match, communication was fine between us, but after the match - that was different!

Subject H: Maybe they think being deaf means being disabled. I feel that if they go to the pub after a match, and have to say they lost 4-1 or whatever to a deaf team, then the hearing people there may say, 'Your team must be crap, they are worse than the disabled'. Maybe they would feel depressed by that. ... I wonder how the hearing teams in our league feel, because the deaf team are at the top of Division 4 at the moment. They are all below us, and maybe they feel embarrassed.

This deaf footballer also hints at the depth of feeling such attitudes can generate amongst deaf players with the following remark:

What would happen if a deaf-blind team beat a hearing team? There would be a riot $!^{48}$

Although in some ways this is a humorous throwaway remark, it was expressed with an intensity which suggested not only a contempt for such attitudes, but a real resentment of the way deaf people feel they are seen and treated by hearing people in their daily lives. Padden (1980) feels that conflict promotes deaf identity, and the above comment would seem to suggest that such experiences have strengthened the way those involved view themselves as deaf people. This process of apparent conflict between deaf and hearing players shows no sign of changing in the near future, and history suggests that change may still be some way off:

Subject H: It's a strange thing - [team name] DFC are in a hearing league now, but we were first in a hearing league in 1907. We dropped out, and played in lots of other leagues, but now we are back in the original league, and things are still the same. The research I have done shows the same attitude problems back then. 


\section{Tensions within the Deaf Community - Some Examples from Deaf Football}

It is possible to gain an impression from certain writings on the deaf community that all its members share a sense of closeness and bonding and that any conflicts which may exist are with outsiders, such as those outlined above. ${ }^{49}$ However, there are examples from deaf football which show how some of the tensions that exist in other communities are also present within the deaf community. The way in which deaf football in Glasgow formerly mirrored the religious segregation between Catholics and Protestants in the city is one example of this. ${ }^{50}$ Rivalries between English and Scottish football clubs also appear to have been present in deaf football. Former players from England recall their trips to play in Scotland during the 1970s:

When we went to [town in Scotland] - do you remember, we must have gone there 20 times? - no-one liked going there. It was always us who had to go to [town in Scotland], they never had to come to [town in England] ... Sometimes we beat them, sometimes they won. If we beat them, we wouldn't stop there at night and have a drink, because we knew there would be trouble. We used to set straight off for home, and maybe stop somewhere halfway, somewhere like Carlisle for a few drinks. ${ }^{51}$

The political situation in Ireland is also mirrored to some extent in deaf football, in the experience of this Irish international:

Really, it's a sensitive issue when players from the north - from Ulster - are picked for the team. The other players from the south don't exactly make a fuss and congratulate you - they look at you at little bit warily. They accept you, but not fully. Players from the north are proud to be picked, they are proud to be Irish, but they are definitely looked at differently by the southern players. I worry that it might affect teamwork if players are isolated in that way. ${ }^{52}$

These examples show that, in many respects, certain tensions within the deaf community are no different from those found in other communities. Tensions are a part of community life, both within and between communities, as demonstrated in the relationships that sometimes exist between deaf and hearing footballers, both as team-mates and opponents. It would be naïve to expect shared deafness alone to negate any tension between individuals and groups of deaf people; shared characteristics do not necessarily override differences and disagreements in other cultural groupings, and the members of the deaf community are no different from anyone else in this respect.

\section{Raising Awareness through Football}

Despite the negative attitudes faced by deaf players, some still see football as an opportunity to raise awareness: 
Subject H: Most hearing - well, not all, but some - they think that disabled and deaf are the same. It's been the same throughout history, there's always been that discrimination label. But if we can show them that we can play football, and we aren't disabled, then maybe things will change.

Subject G: People can see that deaf people can play football, and be successful. We have shown we are not stupid, we can do things like playing football. We have raised awareness by being at the top of the league - we've only lost one game all season.

Even when deaf players consider trying to make a positive move to improve deaf awareness, there are perceived difficulties:

One time, I thought I would run a deaf awareness course, and I wrote a letter to send to all the clubs, asking them to send a representative. In the end I let it drop, because I thought that it might make the situation worse. I mean, how would they feel if they received a letter which said, 'I would like to invite you to a deaf awareness course.'? They would probably think it was really cheeky! But still, the attitude of some people out there is terrible. $^{53}$

These experiences, and the way in which the deaf players react to them, strengthen the argument that deaf football is indeed a part of deaf culture. One of the criteria given by those who attempt to define deaf community membership and deaf cultural activities is that they occur as a result of shared experience. As the examples given throughout this article illustrate, the experiences of many deaf players are very similar; whether playing for or against hearing teams, and in the reasons they give for joining deaf teams. The beliefs held by deaf people about the way they are perceived and treated by hearing people, and the feelings of being in regular conflict with the hearing majority, are also evident in many of the statements they make regarding hearing opponents. Once again, the notion of conflict strengthening deaf identity can be seen to apply when deaf teams are involved in football with hearing opponents.

\section{Deaf Sport - What's the Point?}

Given that deaf sport seems to serve a similar role to that of sport for hearing people, it might be argued that there seems no reason to have distinct teams of deaf and hearing sportsmen and women. After all, deaf sportsmen and women have always been involved in sporting contests with hearing competitors, either as teams or individuals, so is there really a need for separate deaf and hearing teams? Stewart argues that deaf sportsmen involved in hearing sport do not gain the same benefits as hearing participants, particularly on a social gratification level. Much of this is due to the lack of communication between deaf and hearing teammates, and because of the perceptions of the other group that each brings to their 
involvement with the sport. There is evidence of deaf players in hearing teams being excluded, through a lack of awareness, from the social activities which surround participation in all sport. However, this does not stop some hearing versions of sports, especially team games such as football, being regarded as superior to their deaf counterparts. This is largely based on the advantage of being able to hear instructions and warnings from team-mates without the need to look away from the ball..$^{54}$ Given the importance of the social aspects of sports participation, Stewart contends that deaf sport caters for the social needs of deaf sportsmen, whilst involvement in hearing sport provides what he terms physical gratification; thus deaf and hearing sport play two distinct roles for deaf sportsmen and women.

In this respect, involvement in deaf football is in essence often more of a cultural than a sporting activity. On the other hand, competing alongside hearing footballers, as a member of a hearing team, is seen as being more sporting in focus, often with little social interaction between deaf and hearing members. Competing for a deaf team against a hearing team can be a cultural event, with the use of sign language for covert communication (covert from the hearing team) being an expression of deaf culture, as well as a useful tactic. Deaf footballers often try harder against hearing opponents, as a reaction to the way they are treated and perceived by the general hearing majority. This cultural aspect of deaf football is what makes it attractive to both existing members of the deaf community and deaf persons for whom it may be the first introduction to this particular social group..$^{55}$ Therefore, deaf football plays a central part in the social and cultural life of the deaf community, on global, national, regional and local levels.

Deaf football can act as an empowerment process for deaf people, allowing them to compete and succeed in a way often denied to them in other areas of life. Success can breed success, as shown by the number of successful deaf footballers who have gone on to hold positions of power within the various deaf organizations. Furthermore, deaf footballing champions can act as role models for young deaf people to emulate and respect, serving as counterpoints to the many hearing footballing icons children have today. Deaf football can act as a route by which deaf people who are not members of the deaf community can gain knowledge of - and access to - the community, and all its social and cultural activities. This in turn can act as a support and information network of people with similar outlooks, experiences and backgrounds. Deaf football can fill a void created by a lack of opportunities and social interaction resulting from the way deaf people are perceived and treated by the hearing majority. In doing so, deaf people can gain self-respect and confidence that can be carried forward to other activities. Moreover, deaf football can act as a means of escaping the pressures of everyday life as a member of a group which feels itself to be an oppressed minority. Deaf football provides opportunities for deaf people to meet other members of what is a geographically dispersed group, and to make and renew friendships. 
It seems likely, given the central role that football has played in the life of the deaf community over a long period of time, that if the social and cultural activity that is deaf football had not occurred, it would have been necessary to invent it. It seems impossible to conceive of any other activity which could replace it or serve the same purpose on the same scale. Other deaf cultural activities play an important role in the life of the deaf community, but none has brought so much benefit to so many people over such a long period.

Sports play an important role in the lives of deaf people. We participate in athletic activities for a variety of reasons: for health and fitness, for recreation, for social interaction, and for the pursuit of excellence in sports through training and competition. ${ }^{56}$

And of course, deaf people like to play football simply because they enjoy it. Whether they will continue to have the opportunity to do so is uncertain, as deaf football experiences a period of steady decline. Deaf football clubs are closing all around the country, a trend which has always been an integral part of deaf football. However, fewer new clubs are being formed to replace them, and so the number continues to decrease. The Scottish Deaf Cup is no longer viable due to declining numbers, and the British Deaf Cup seems to be slowly moving towards a similar fate. Changes in educational policy for deaf children mean that many no longer have access to football through after school activities. The closure of Deaf Schools in favour of integrated education means that many young people no longer have the access route into the networks of the deaf community that such schools traditionally provided.

In many ways, the changes deaf football is undergoing reflects the wider experiences of the deaf community. The deaf club is no longer the focus of deaf cultural life for young deaf people, and the lifelong ties formed in deaf schools, which served as an entry route in the life of the deaf community are not widely available to deaf children, as placement in mainstream schools replaces the discrete provision of the past. This natural progression from school to community involvement via deaf club was the lifeblood of not only deaf football teams but the whole community. Without it, deaf life is changing, and integration in school is leading to greater integration in other areas of life. This is not necessarily a bad thing, as it reflects the growing confidence of deaf people, who are more likely to demand equal access to jobs and careers, and are more confident about mixing with hearing people on a daily basis.

The impact of these changes on deaf football is radically changing the whole nature of deaf involvement in playing the game. Integration with hearing footballers, whether as members of a hearing team or as opponents, has always been a part of deaf football, often offering an alternative type of game, which was often seen as being of a higher standard. Deaf football offered more socialization and the chance to become part of a community of people with similar outlooks and experiences. The trend nowadays seems to be away from playing with or 
against hearing teams as an alternative, to becoming the only way deaf players can find a game. Even so, it appears unlikely that deaf footballers will completely disappear from the game, even if their involvement is confined to playing in hearing leagues, either as individuals or as members of a deaf team. Deaf football may well play a different role in the life of the deaf community in the future, but it seems likely to continue to be an important part of the social and cultural lives of individual deaf people.

\section{University of Central Lancashire}

\section{NOTES}

1. D. Brien (ed.), Dictionary of British Sign Language (London: Faber and Faber, 1992), pp.1-134.

2. P. Higgins, 'Outsiders in a Hearing World' in S. Gregory and G. Hartley (eds.), Constructing Deafness (London: Pinter, 1980), pp.23-30.

3. C. Baker and D. Cokely, American Sign Language: a Teacher's Resource Text on Grammar and Culture, Vol.1 (Maryland: Clerc Books, 1980) pp.90-92.

4. C. Padden, 'The Deaf Community and Deaf Culture' in Gregory and Hartley (eds.), Constructing Deafness, pp.40-45.

5. A. Davies, Hearing in Adults (London: Whurr, 1995), p.24.

6. For more information on the history of deaf football, see M. Atherton, D. Russell and G.H. Turner, 'Playing to the Flag: A History of Deaf Football and Deaf Footballers in Britain', The Sports Historian, 19, 1 (May 1999), 38-60.

7. J.W. Loy and G.S. Kenyon, Sport, Culture and Society (London: MacMillan, 1969), p.15.

8. For example, sport features regularly in the pages of Deaf and Dumb Times, British Deaf Mute and Deaf Quarterly Nems, amongst others.

9. D. Stewart, Deaf Sports: the Impact of Sports mithin the Deaf Community (Washington: Gallaudet University Press, 1993).

10. R. Holt, Sport and the British. A Modern History (Oxford: Clarendon, 1989).

11. Deaf and Dumb Magazine (1874), 77, 141, 159.

12. Holt, Sport and the British, p.347.

13. R. Taylor and A. Ward, 'Kicking and Screaming: Broadcasting Football Oral Histories', Oral History, 25,1 (1997), 57-62.

14. Ibid.

15. L. Lawson, 'The Role of Sign in the Structure of the Deaf Community' in Gregory and Hartley (eds.), Constructing Deafnes, pp.31-4.

16. Holt, Sport and the British, pp.336-7.

17. H. Lane, R. Hofmeister and B. Bahan, A fourney into the DEAF-WORLD (San Diego: DawnSign Press, 1996), p.30.

18. Higgins, 'Outsiders in a Hearing World', pp.23-30.

19. Baker and Cokely, American Sign Language, p.36.

20. Stewart, Deaf Sports, p.37.

21. Holt, Sport and the British, p.367.

22. A. Wohl and E. Pudelkiewicz, 'Theoretical and Methodological Assumptions of Research on the Processes of Involvement in Sport and Sport Socialization', International Reviem of Sports Sociology (IRSS), 7 (1972), 69-84.

23. Stewart, Deaf Sports, pp.126-31.

24. All interview subjects remain anonymous, owing to the nature of some of the comments made. All references to places and clubs have also been removed.

25. Taylor and Ward, 'Kicking and Screaming', 59.

26. B. Woll, 'International Perspectives on Sign Language Communication', International fournal of Sign Linguistics 1, 2 (1990), 107-20.

27. Interview subject D.

28. Holt, Sport and the British, pp.153-9.

29. Wohl and Pudelkiewicz, IRSS, 74 . 
30. P. Davies, I Lost my Heart to the Belles (London: Heinemann, 1995).

31. Interview subject $\mathrm{F}$.

32. Holt, Sport and the British, p.346.

33. Interview subject $\mathrm{G}$.

34. Holt, Sport and the British, pp.154-5.

35. Stewart, Deaf Sports, p.73.

36. Stewart, Deaf Sports, p.1.

37. Interview subject $A$.

38. This view is shared by Stewart, Deaf Sports, p.126. Examples of successful deaf footballers becoming successful in other areas of life include Jeff McWhinney, Chief Executive of the British Deaf Association and former Irish deaf international footballer; and Doug Alker, Chair of the Federation of Deaf People and the first profoundly deaf person to become a fully qualified FA coach. Doug was also a successful manager in semi-professional football in Lancashire.

39. P. Ladd, 'Making Plans for Nigel: the Erosion of Identity by Mainstreaming' in G. Taylor and J. Bishop (eds.), Being Deaf; the Experience of Deafness (London: Pinter, 1991), pp.88-96.

40. Interview subject I.

41. Interview subject $D$.

42. Davies, I Lost my Heart, pp.77-81.

43. Stewart, Deaf Sports, pp.33-4.

44. Lawson, 'The Role of Sign', pp.31-4.

45. Interview subject $C$.

46. Interview subject $\mathrm{F}$.

47. Interview subject $\mathrm{H}$.

48. Interview subject I.

49. As an example of such writing, see B. Kannapell, 'Inside the Deaf Community' in S. Wilcox (ed.), American Deaf Culture (Burtonsville: Linstock, 1989), pp.21-8.

50. Glasgow DFC have until quite recently been the club for Protestant deaf players, whilst St Vincent's have generally been the Catholic DFC in the city. This situation is now changing, with the two clubs becoming more integrated.

51. Interview subject $C$.

52. Interview subject $\mathrm{D}$.

53. Interview subject I.

54. This view was expressed by a number of deaf footballers during research interviews.

55. Stewart, Deaf Sports, p.152.

56. D.K. Ammons and M.S. Miller, 'Sports, Deafness and the Family', in C.J. Erting and R. Johnson (eds.), The Deaf Way: Perspectives from the International Conference on Deaf Culture (Washington: Gallaudet, 1994), pp.542-4. 